\title{
METALINGUAGEM NO MUSEU AFRO BRASIL: PONTES ENTRE CURADORIA E O FAZER ARTÍSTICO
}

\author{
Carla Brito Sousa RIBEIRO ${ }^{1}$
}

RESUMO: Proponho que a exposição do acervo do Museu Afro Brasil (SP) possui características muito representativas da interseçáo entre os ofícios de criação e curadoria de arte e sobre o trato da memória institucional, através de práticas pouco convencionais de exercício da expografia. À vista disso, busco refletir sobre uma interpenetração entre curadoria, fazer artístico e expografia, e trazer aportes das análises sobre curadoria, criação artística e arranjos metalinguísticos no museu estudado. Apresento a exposiçáo como memorial institucional - com base em conversas e entrevistas com colaboradores, do "diálogo ausente" com o curador-diretor-artista e da análise de material bibliográfico e obras do acervo - por compreender a exposição como um imaginário composto por montagens de imagens criadas por Emanoel Araújo. Para comunicar a singularidade da exposição, trago uma perspectiva dos objetos em exibição possibilitada pelos registros de campo e as análises a partir dele, em diálogo com teóricos das artes e humanidades sobre práticas curatoriais, polissemia da imagem e o papel da cenografia. Discuto o fazer artístico da curadoria e o ofício de curador-artista calcado na figura de Emanoel Araújo, que toma como base A Mão Afro-Brasileira. Por fim, tenciono a relação texto-imagempúblico, ao passo que, apesar de não haver consenso sobre as possibilidades criativas do fazer curatorial, afirmo que Emanoel Araújo e equipe ultrapassam o usual esperado desta prática, posto que os limites sobre a topografia dos objetos dispostos e os recursos sensoriais da cenografia são extrapolados.

PALAVRAS-CHAVE: Museu Afro Brasil. Curadoria. Emanoel Araújo. Metalinguagem. Expografia.

\footnotetext{
1 Universidade Federal de Santa Catarina (UFSC), Florianópolis - SC - Brasil. Mestre em Antropologia Social. Desenvolveu a pesquisa que deu origem à dissertação de Mestrado com financiamento pelo CNPq. ORCID: https:// orcid.org/0000-0001-7199-6253. cbsribeiro@yahoo.com.br.
} 


\section{METALANGUAGE AT AFRO BRASIL MUSEUM: BRIDGES BETWEEN CURATORIAL WORK AND ART MAKING}

ABSTRACT: I propound that the collection exhibition of Afro Brasil Museum located in São Paulo, Brazil, features characteristics that well represent intersections between art creation and curatorial work, besides its dealt with institutional memory through less conventional exhibit designs. Thus, I seek a reflection about the interchange between curatorial work, art making and metalanguage arrangements within this museum. I introduce this exhibition as an institutional memorial - based on conversations and interviews with the museum staff, "absent dialogues" with its curator-director-artist and by the analysis of bibliographic material, so as the collection itself - due to my understanding of the exhibition as an imagery formed by composite images set by Emanoel Arauijo. In order to communicate the singularity of this exhibition I bring a perspective of the objects exhibited, by means of the registers of fieldnotes and on, undertaking a dialogue with scholars from arts and humanities about curatorial work, the polysemy of image and the role of scenography. I discuss the art making of curatorial work and Emanoel Araújo's métier as curator artist, supported by his concept A Mão Afro-Brasileira (The Afro-Brazilian Hand). In conclusion, I stress the relation textimage-public in order to communicate the singular aspects of its exhibition. Whilst the absence of consensus toward creativity and art agency while designing exhibitions, I assert that Araujo and his team strain the usual expectations on curatorial practice hence the limits of topographic arrangements and scenography schemes as a sensorial tool are extrapolated.

KEYWORDS: Afro Brasil Museum. Curatorial work. Emanoel Araújo. Metalanguage. Exhibit design.

\section{Introdução}

As particularidades que circundam a constituição do Museu Afro Brasil, a partir da coleção inicial de Emanoel Araújo - artista visual multifacetado, principal curador das exposiçóes e, até o momento, único diretor do Museu -, possibilitam a reflexão sobre o fazer curatorial e os entremeios envolvendo seus ofícios como artista e curador. Além das interseçóes entre curadoria e criação artística, este texto também aborda expressóes de metalinguagem percebidas nas exposiçóes do Afro Brasil, que possuem fortes características autorais do trabalho de seu curador, agente central desse processo metalinguístico, além do elo que conecta o presente, o passado e a construção da memória institucional para o futuro do Museu. Isso posto, busco elaborar sobre duas dimensóes dessas expressóes de metalinguagem: 
1. A exposição do acervo como memorial institucional; e

2. O fazer do artista curador ou curador artista.

Efeitos da prática curatorial e expográfica, essas dimensões confundem-se e retroalimentam-se, de maneira semelhante ao processo criativo notado no interior do Museu. Aproximar o olhar sobre estes aspectos possibilita a reflexão sobre os meandros da cenografia e arte instalação, sobre os poderes de criação da curadoria, e sobre o cerne do objeto museológico, o fato museal, que segundo Waldisa Rússio C. Guarnieri (2010, p. 123), "é a relação profunda entre o homem - sujeito conhecedor -, e o objeto, parte da realidade sobre a qual o homem igualmente atua e pode agir".

As reflexôes que seguirão foram inspiradas pela abordagem etnográfica do Museu Afro Brasil no ano de 2017, no qual ao longo de quase cinco meses realizei pesquisa de campo para elaboração da dissertação de Mestrado Que "Afro" é esse no Afro Brasil? (RIBEIRO, 2018). Frequentando o Museu ao menos quatro vezes por semana, entrevistei colaboradores e acessei os processos curatoriais, bem como acompanhei as reações e elaboraçóes dos visitantes sobre as mostras. No texto da dissertação, narro em detalhes a escolha metodológica complementar à etnografia como "diálogo ausente" que empreitei com Emanoel Araújo (2010). A ausência física se deu pelo posicionamento do autor com relação à pesquisa, que acabou por direcioná-la a registros já existentes. Tive acesso a um vasto conteúdo de entrevistas concedidas a outros pesquisadores e jornalistas, bem como a catálogos, exposiçôes em cartaz e registros biográficos. Ademais, todas as experiências e encontros realizados, as longas horas na biblioteca do museu e o acompanhamento das visitas do setor educativo foram devidamente registrados nos cadernos de campo. Por meio destas aproximaçóes, pude perceber aspectos peculiares da curadoria deste Museu que, desde 2004, sustenta um projeto político de comunicação e educação; examinar o conceito que vem se aprimorando através de sua existência pode ajudar a potencializar a fruição deste espaço de memória coletiva, e evidenciar a sofisticada tessitura de ideias nos objetos de suas coleçóes. O discurso institucional, comunicado especialmente por suas exposiçóes, representa valiosa contribuição para áreas como a dos estudos étnico-raciais e de relaçóes interétnicas. As questóes suscitadas fomentam o debate sobre diversidade na historiografia brasileira, nas artes, na antropologia e nas ciências sociais em geral. Analisar o discurso curatorial no Museu Afro Brasil também pode despertar reflexóes na área da museologia, no tocante à curadoria, ao colecionismo, e às práticas de museografia e expografia.

O Museu Afro Brasil é uma instituição que não cabe em uma só categoria. A depender de como e por quem é observado, pode ser considerado um museu 
de história, de temática etnográfica, voltado às artes, ou mesmo um museu afro-brasileiro. A pluralidade de seu acervo o torna capaz de representar quaisquer das categorias expostas, porém, não é possível limitar o seu escopo a apenas uma delas. Localizado no interior do Parque Ibirapuera, na capital do Estado de São Paulo, aloca-se no Pavilhão Padre Manoel da Nóbrega, com vastos $11 \mathrm{mil} \mathrm{m}^{2}$. A instituição aborda as relações profundas entre África e Brasil, e para tanto, versa sobre o que faz do Brasil, Brasil, além de abarcar expressóes africanas e as de um Brasil Afro-Brasileiro.

O que venho chamando de práticas de metalinguagem no Afro Brasil não são ações deliberadas e organizadas por sua equipe. Não há delimitação essencialmente processual nas práticas observadas, e, por vezes, o desenrolar do processo não se dá de maneira consciente por parte de seus autores. É fato que a ausência de sistematização acrescenta um grau de dificuldade à construção deste texto, tendo em vista a necessidade de elaborar uma lógica para comunicar as percepçóes sobre as práticas e processos desenvolvidos no Museu Afro Brasil. Acrescenta-se ainda a noção de que as escolhas curatoriais aqui estudadas são, em grande medida, opçóes iconográficas que fogem à escrita alfabética e à comunicação textual, sobre as quais me deterei melhor mais adiante. Cabe dizer que existe uma lacuna entre a expografia do Afro Brasil, revelada majoritariamente através de imagens, e a escrita deste artigo, que comunica este processo por meio textual. Sobre essa lacuna pretendo construir pontes que contribuam para o destaque da complexidade, abrangência e relevância dos temas abordados pelo Museu Afro Brasil. Por ora, vale mencionar que o que entendo por imagem está em consonância com Jacques Aumont (2011, p. 272), a saber:

Insistimos até agora no fato de que a imagem se define como um objeto produzido pela mão do homem, em um determinado dispositivo, e sempre para transmitir a seu espectador, sob forma simbolizada, um discurso sobre o mundo real.

Usadas como meio de transmissão de um discurso, as imagens no Museu pesquisado foram observadas enquanto conjunto, capaz de revelar as práticas de metalinguagem. É necessário observar que o conceito de metalinguagem precisou ser expandido para além da linguística, sendo ora empregado por metonímia, ora por metáfora. Pesquisar o museu, que possui entre suas razóes de existir a pesquisa, pode ser considerado aqui como ato de dimensão metalinguística. Sobretudo quando a pesquisa serve ao propósito de reflexão museológica. No mesmo sentido, a produção acadêmica sobre o Museu Afro Brasil é também 
elaboração de memória textual sobre a instituição - local de memória por definição -, testemunhos possíveis da trajetória criativa nos entremeios das identidades afro-brasileiras.

É comum que dicionários e manuais técnicos, especialmente na área da linguística e gramática sejam as principais fontes que usamos para exemplificar o que é a metalinguagem. De modo extremamente sucinto, pode-se dizer que operaçóes de metalinguagem ocorrem quando se utiliza a linguagem para se referir à própria linguagem. Nesse sentido é possível entender as imagens criadas para a exposição do acervo no Museu Afro Brasil enquanto a linguagem examinada para pensar a expressão metalinguística. Em suma, o que trato por práticas de metalinguagem no exercício curatorial e expográfico do Museu são ações observadas empiricamente, que possuem uma dimensão reflexiva (no sentido de reflexo, espelhamento) de sua própria constituição. Estes atos se materializam em suportes semanticamente expansíveis e podem ajudar a pensar curadoria e criação artística. Não intenciono propor uma ruptura com os sentidos tradicionalmente utilizados para metalinguagem na linguística, ou no cinema; mesmo que as reflexóes a seguir venham a expandir o seu sentido, devo reconhecer que a construção de terminologias é condição inerente ao exercício científico, e que, quanto mais específica é a delimitação terminológica, e quanto mais especializada a linguagem, mais aparatos para a defesa de legitimidade e emancipação a área possui. Inevitável, no entanto, é romper com os "socioletos" (PORTELA, 2012, p. 5), que refletem a adoção de um léxico restritivo, ainda que sirvam aos propósitos de constituir identidade e corpo teórico para o campo científico que delimitam.

\section{O memorial de si}

O que outrora no campo museológico denominava-se exposição permanente é preferivelmente chamada exposiçâo de longa duração, que evidencia a necessidade de revisão constante dos objetos expostos, tanto por fatores de conservação e salvaguarda, quanto a fim de dinamizar o conceito e aumentar a participação do público. A partir de como será recebida a exposição, bem como o resultado das pesquisas com o público, espera-se a reconstrução da narrativa, a fim da democratização dos espaços museais.

No caso da exposiçáo do acervo do Afro Brasil, embora nunca tenha sido completamente reformulada, passou ao longo de sua existência por revisóes e acréscimos cotidianos que mudaram consideravelmente a proposta inicial, ao menos visualmente. Quando de sua concepção, a curadoria da exposição de 
longa duração do Museu Afro Brasil foi pensada por uma equipe multidisciplinar, composta por profissionais das áreas da antropologia e museologia, por especialistas em arte e história africana, artistas visuais, entre outros. Emanoel Araújo, seu diretor, possuía papel de destaque na formação do Museu, pois além de sua experiência de criação em arte afro-brasileira, e do período de gestão de museus como o Museu de Arte da Bahia (1981-1983) e da Pinacoteca do Estado de São Paulo (1992-2002), esteve à frente da curadoria de exposiçóes como A Mão Afro-Brasileira (1988), Vozes da Diáspora (1993), Herdeiros da Noite: fragmentos do imaginário negro (1994), Negro de Corpo e Alma (2000), e Para Nunca Esquecer: Negras Memórias/ Memórias de Negros (2002). Todas exposiçóes que buscaram, com poucos antecedentes, destacar a contribuição da população afro-brasileira na história da construção nacional em diversos âmbitos, na contramão do ocultamento do povo negro no arranjo do imaginário nacional. $\mathrm{O}$ discurso dessas e outras exposiçóes pregressas trazia a ênfase da afrodescendência nas artes, na técnica, na criação e no trabalho, para além do lugar do sofrimento provocado pela escravização.

O ofício de curador e pesquisador impulsionou ainda mais o tino colecionista de Araújo, que vinha realizando aquisiçôes desde os anos 1980 para incorporar a seu acervo pessoal. Com o aumento das curadorias que realizou, passou a negociar a compra de obras expostas nas mostras, tanto para sua coleçáo particular, quanto para os museus que dirigiu, tendo aumentado consideravelmente o rol de artistas negros nas coleçóes da Pinacoteca de Sáo Paulo. Sua coleção privada foi o aporte inicial para os núcleos conceituais da primeira exposição do Museu Afro Brasil, que ainda estruturam as grandes temáticas abordadas. Os temas escolhidos pela equipe de curadoria inicialmente foram: História e Memória; Arte Africana; Trabalho e Escravidão, e Festas e Religiosidade. Divididos em núcleos, estavam delimitados por cores e a volumetria usada náo possuía a densidade que caracteriza a exposição atualmente. À frente do Museu, Emanoel Araújo realizou outras diversas aquisiçóes para o acervo, incorporando alguns conceitos de exposiçóes de curta duração, bem como parte expressiva dos objetos que as compunham. 
Figura 1 - Vista da exposição do acervo em 2010

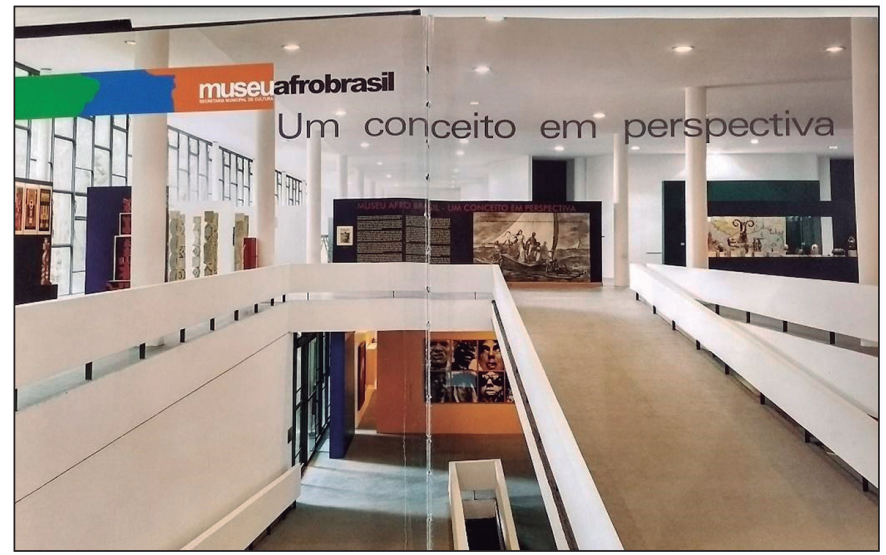

Fonte: Museu Afro Brasil.

Figura 2 - Vista da exposição do acervo em 2017

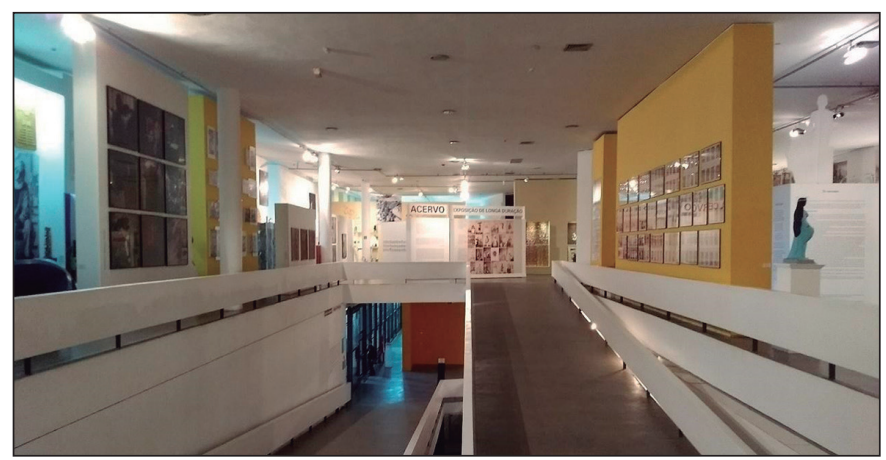

Fonte: Elaboração própria.

Através do comparativo entre as figuras 1 e 2 , pode-se perceber, em especial, a expansão da altura das paredes que dão suporte às obras e o uso de iluminação artificial em detrimento da luz natural, como consequência. Porém, as imagens não são capazes de tornar evidente o processo de adensamento dos objetos em exposição ao longo dos anos. Trata-se de um processo constante em que são desmontadas exposiçóes de curta duração e, negociadas aquisiçóes de obras ou objetos expostos, que por sua vez são inseridos à exposição. Por vezes também são reaproveitados painéis com plotagem de fotografias, gravuras, poesias, e em alguns casos, textos. O que Ana Lúcia Lopes, então Coordenadora de Planejamento Curatorial, chamou de "retroalimentação" ocorre cotidianamente 
no Museu. Por exemplo: um visitante frequente pode notar que objetos anteriormente expostos na exposição Bijagós (2008), doados pelo povo de mesmo nome, residente na Guiné Bissau, compóem uma sessão da exposição de longa duração, ou que obras da produção artística popular na exposição Entreolhares: poéticas d'alma brasileira (2016) foram inseridas nos corredores laterais da exposição do acervo.

Deste modo, parte importante da narrativa predominantemente visual que se desenvolve na exposição de longa duração é oriunda de exposiçóes de curta duração. É algo que, levado ao contexto de produção acadêmica, remete-nos à autocitação, ou, como figura de linguagem, à metalinguagem, na qual a linguagem da exposição retoma recortes de criaçóes imagéticas pregressas que se encaixam na construção de uma narrativa única para a grande exposição de longa duração. A metalinguagem desvela o museu como uma sorte de memorial de si. É a exposição do acervo revelando a sua própria constituição, falando sobre o museu e sobre as criaçóes discursivas que por ali passaram. No entanto, este memorial não é auto evidente, é necessário ter conhecido as exposiçóes anteriores do Museu, talvez ter sido visitante assíduo, ou mesmo leitor dos catálogos disponíveis na Biblioteca Carolina Maria de Jesus. Folhear as páginas dos catálogos de exposiçôes produzidas ao longo dos 15 anos de existência do Museu Afro Brasil é como estar em uma escavação arqueológica, durante a qual descobrimos a genealogia de ideias que embasaram núcleos expositivos, notamos que obras emprestadas temporariamente para a realização de mostras foram adquiridas para a coleção, e retomamos conceitos originais em profundidade. Neste sentido, ainda que não seja formalmente reconhecida como um memorial de sua própria trajetória, a exposição do acervo do Museu Afro Brasil utiliza de recursos de sua própria história na construção de seu cartão de visitas principal.

Outro exemplo de como os conceitos da exposição de longa duração foram se desenvolvendo, e este mais propício para ressaltar como os conceitos iniciais tomaram forma e foram aprimorados, é a instalação Navio Negreiro, um dos pontos altos da exposição do acervo. Alocada em um ambiente de luz baixa, cercado por paredes móveis, de onde periodicamente se projeta um canto feminino profundo e o barulho das águas, o centro da instalação é a carcaça de uma embarcação em madeira rústica. A iluminação direta sobre o barco e a criação de um ambiente distinto do externo são recursos que reforçam a ambientação. As paredes que o cercam, tomadas por gravuras e mapas, ora retomam a localização dos principais portos em África, de onde saíam as embarcaçóes a serviço do tráfico de pessoas escravizadas, ora servem de suporte a objetos utilizados para torturar os cativos. São muitas as informaçóes e estímulos neste espaço, inclusive 
textuais: poemas como o Navio Negreiro de Castro Alves e trechos de citação do trabalho de Fernando Henrique Cardoso, que enfatiza a persistência do racismo no país. O canto supracitado advém de um vídeo que justifica o barulho das águas que se pode ouvir do lado externo; traz imagens do alto-mar, a percepção de seu balanço e outro conjunto iconográfico que faz par às imagens das paredes ao redor: são desenhos e fotografias em preto e branco não datadas, que retratam mulheres e homens negros em uma perspectiva de passividade, representados enquanto trabalham, por diversos ângulos. São retratos que exploram condiçóes de desigualdade e que hoje conhecemos como a iconografia icônica do período escravocrata.

Figura 3 - Instalação Navio Negreiro em 2010

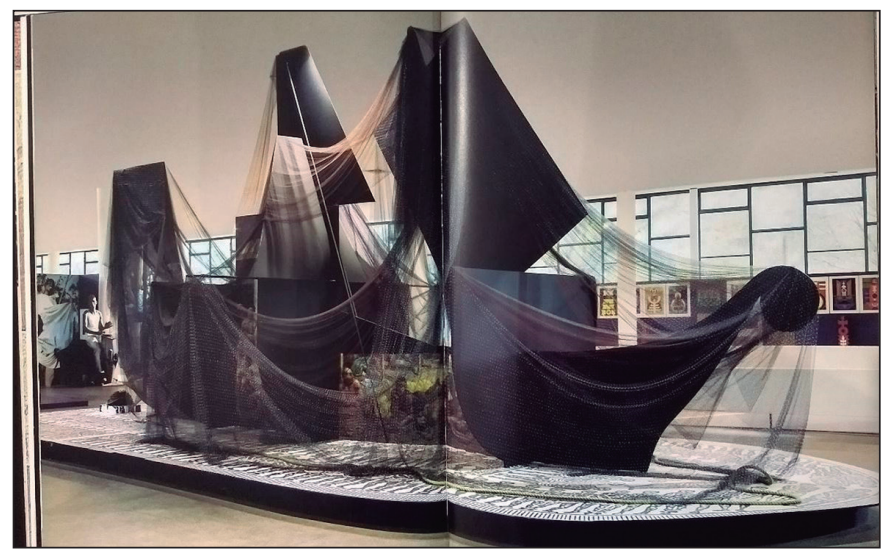

Fonte: Museu Afro Brasil.

Figura 4 - Instalação Navio Negreiro em 2017

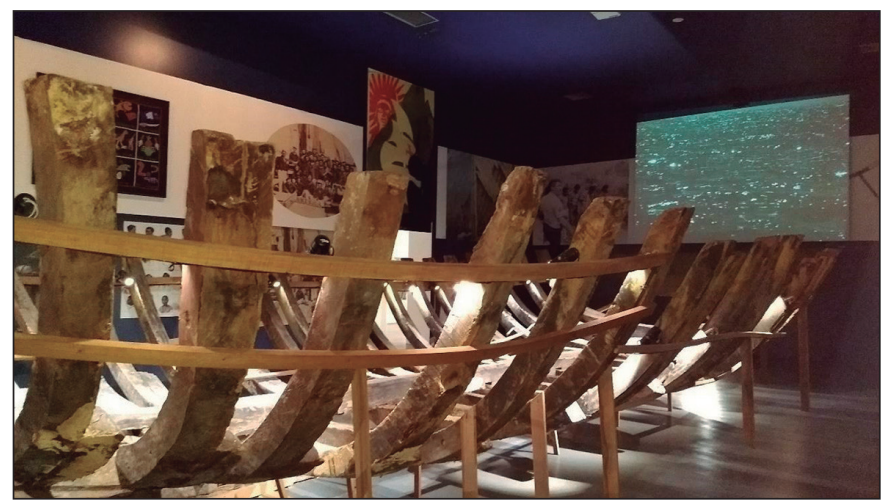

Fonte: Elaboração própria. 
A versão anterior da instalação apresentava o conceito de uma embarcação, reproduzida com painéis e o que parece ter sido um tecido transparente. De acordo com interlocutores do setor educativo da instituição, Emanoel Araújo soube de um naufrágio na costa baiana, e pediu para que reservassem as madeiras da embarcação, que teriam sido trazidas por uma equipe para integrar o acervo do Museu. Ao longo dos anos os recursos se aprimoraram e a execução do conceito da instalação passou a tomar forma mais dramática, chegando a incorporar painéis oriundos de exposiçôes de curta duração e novas aquisiçôes de objetos. Plotagens, textos e recursos de cenografia foram inseridos à narrativa de modo a fazer surgir uma nova instalação.

\section{A Metalinguagem da Mão Afro-Brasileira}

Saindo do espaço destinado à instalação Navio Negreiro, outros objetos em exposição no Museu Afro Brasil também incitam a pensar sobre períodos de nossa história. De maneira sincrônica, estão em exposição retratos da corte portuguesa e membros da alta sociedade imperial, junto a pertences e mobiliário que remetem a esta distinta parcela do Brasil oitocentista. A presença deste agrupamento de objetos na narrativa da exposição retoma signos do apartheid à brasileira. Ao redor deles, os anônimos e nomeados retratados são unanimemente brancos, e seus pertences, feitos em metais nobres. Enquanto estes sujeitos estão distanciados de quaisquer ideias ligadas a ofícios e trabalhos manuais, ao lado, é possível avistar utensílios domésticos em madeira e ferro, fôrmas de pão de açúcar, tachos para produzir melado e outros derivados da cana-de-açúcar, ferramentas ligadas ao engenho e objetos do ciclo açucareiro. Este é o universo simbólico que se cristalizou como espaço de memória visual que associamos à população africana e afro-brasileira, uma redução limitada que não permite que estes indivíduos sejam percebidos para além de sua força de trabalho escravizada.

Devo ressaltar que nenhuma dessas associaçóes é incitada através de elementos textuais. Esta é uma leitura particular dos objetos expostos, confirmada pelos porta-vozes da instituição, com os quais estive em diálogo. Distintos elementos revelam e reforçam os abismos sociais através da mostra, seja por meio das cores escolhidas, da propriedade dos objetos ou da cenografia. Como nas fotografias das amas de leite - mulheres escravizadas que eram responsáveis pelos filhos dos senhores - em imagens impactantes nas quais seus olhares dizem muito. Dizem sobre a continuidade da servidáo, sobre o cuidado, uma atribuição de mulheres negras, a ausência de escolha. A desigualdade em sua complexidade também pode ser percebida através das liteiras expostas, uma 
delas objeto, vazio, sem referência aos modos de uso; a outra, reprodução da fotografia de 1860: Lady in litter with two slaves, BA. Brazil. De autoria desconhecida, a imagem mostra uma mulher não branca sentada na liteira com seu vestido de densas camadas, enquanto dois homens negros, bem trajados, porém descalços - portanto escravizados - a observam de perto, enquanto a fotografia é realizada. Expressão da permeabilidade da escravidão e da nada simples sociedade colonial, com "pessoas livres de cor" e "libertos", que eventualmente detinham escravizados (CUNHA, 2012). Outros exemplos perceptíveis estão também nas imagens de Canudos devastada após o massacre, nas joias de crioula, nos alicerces do racismo estrutural que, arraigado socialmente, náo nos permite associar prataria, porcelana e liteiras à população de origem ou descendência africana.

Mais à frente, no percurso da exposição do acervo, somos surpreendidos por mais um desafio à lógica binária entre os dois patamares aqui postos. Uma série de objetos de estética colonial, barroca, e mesmo rococó, fazem parte da exposição. Em grande maioria são esculturas, algumas atribuídas a Aleijadinho, talvez o artista que se consagrou como um dos maiores expoentes do Barroco brasileiro. Consta em exposição um painel com a reprodução da pintura do forro da nave central na Igreja de São Francisco de Assis, construída no século XVIII em Ouro Preto, Minas Gerais. De autoria de Manoel da Costa Ataíde, a obra é uma glorificação a Nossa Senhora da Porciúncula. Vista de perto, Nossa Senhora projetada por Ataíde escapa dos padróes estéticos associados a uma mulher branca. Seus traços, portanto, são mais fiéis ao retrato da diversidade e mestiçagem presente no Brasil colonial. Exercendo sua autonomia enquanto artista criador, Ataíde desviou da norma majoritária de seu tempo, e rompeu com a cópia de modelos dos missais importados da Europa para retratar uma mulher que lhe parecesse mais próxima à realidade brasileira.

A chave para entender a presença expressiva de objetos produzidos durante o período colonial nas exposiçóes do Afro Brasil está em um conceito desenvolvido por Emanoel Araújo na década de 1980. Os objetos, tenham sido elaborados com pretensão estética ou não, possuem a manufatura como forma majoritária de criação. As mãos através deste trabalho: mãos negras. Mãos africanas e afrodescendentes. Em suma, é este o conceito de $A$ Mão Afro-Brasileira ${ }^{2}$ e é este, a meu ver, o aspecto central para a compreensão das imagens criadas no Museu Afro Brasil.

\footnotetext{
2 A Mão Afro-Brasileira: significado da contribuição artística e histórica (1988), foi, antes de tudo, um projeto de natureza documental, com o intuito de levantar a produção artística e a relevância histórica de personalidades afro-brasileiras. A extensa pesquisa, coordenada por Emanoel Araújo, gerou um catálogo que se tornou referência, e resultou em uma exposição. A segunda edição, revista e ampliada, foi publicada em 2010.
} 
Se o trabalho manual era percebido como indigno e, assim, exclusivo à populaçáo não-branca, se faz necessário entender os ofícios e tarefas nas quais eram empregadas as mãos como produçóes africanas, afro-brasileiras e indígenas. Da construção civil ao acabamento das fachadas, da criação das telhas de barro ao molde das paredes em taipa. Da pintura policromada das naves centrais das igrejas coloniais, às esculturas dos roliços anjos barrocos. ${ }^{3}$ A Mão Afro-Brasileira é, portanto, conceito que funciona como premissa geral para a elaboração da narrativa imagética no Museu Afro-Brasil: a partir da delegação do trabalho a uma parcela da população, a ornamentação (que não era pensada pura e simplesmente por sua finalidade artística) não era vista enquanto ofício nobre, ou relacionado à arte, tal como hoje a percebemos, era também uma atribuição majoritariamente à população negra. Muito do que foi criado e desenvolvido, do design de utensílios e objetos usados na prática do trabalho cotidiano, na cozinha, na roça, no trabalho doméstico, até mesmo o urbanismo dos chafarizes públicos e das fachadas ornamentais coloniais, só existe como testemunho pela obra de mãos afro-brasileiras. Elas estão por trás das pinturas, esculturas e desenvolvimento do país. A atividade da população afrodescendente no Brasil é muito mais premente do que fazem crer as linhas gerais da história oficial. Sabendo da relevância desta linha argumentativa, Emanoel Araújo pincela aspectos fundamentais da obra de 1988 na curadoria do Museu Afro Brasil, quer seja nas exposiçôes de curta ou longa duração.

Do conceito surgem instalaçóes que extrapolam os limites da cenografia e o uso do design como ferramenta auxiliar. São arte-instalaçôes, desdobramentos artísticos. A manifestação da mão afro-brasileira - neste caso, as mãos do próprio artista negro, Emanoel Araújo - é notória na diagramação dos objetos, na densidade escolhida, e na expressividade que provoca. A dimensão metalinguística está no artista afro-brasileiro atuando enquanto curador e gestor de um Museu que representa importante vitrine para a arte e história afro-brasileira.

Elcio Rossini (2012) traz uma importante definição para o conceito de cenografia, que chega ao século XXI com efeito muito além do decorativo. Para o autor, exposiçôes em museus caracterizam mídias em três dimensôes. São criaçóes percorríveis, pensadas para agir na percepção sensível dos visitantes. Deste modo, "cenografia traz a dimensão conceitual do espaço, propondo ritmos e atmosferas geradas pela organização do espaço, da iluminação e do som” (ROSSINI, 2012, p. 162).

3 Para mais informações sobre o trabalho manual no Brasil colonizado, ver Silva (2007), Fonseca (2010) e Jesus (2020). 
Para além da ambientação, o uso que Emanoel Araújo faz da cenografia é o de criação através de composições. Os objetos que conformam a exposição do acervo $^{4}$ não estão dispostos através de uma narrativa sequencial ou cronológica, como é praxe. Eles não estão distribuídos pelo espaço de modo a isolar as suas propriedades e destacar a sua individualidade, ou a individualidade de criação de seus autores. Outrossim, as obras e objetos adensam-se de modo a formar imagens. Imagens que bem poderiam ilustrar $A$ Mão Afro Brasileira em uma futura edição possível. Esta composição iconográfica está atrelada ao processo de "retroalimentação" do qual Araújo é também agente.

Este processo ocorre quando o diretor decide por inserir citaçóes a trabalhos pregressos de sua curadoria como estratégia de metalinguagem, na qual o museu, guardiáo da memória por excelência, insere elementos de sua história para então rememorar o seu processo de desenvolvimento. Em Ogum Historiador, Roberto Conduru (2009) versa sobre o trabalho de Emanoel Araújo como um "artista historiador". Para o autor, o conceito institucional é a denúncia. Denúncia que se volta ao passado, a princípio, para mostrar protagonismo negro, invisibilizado desde a colônia. Para desvelar a cor dos sujeitos que construíram o país, africanos, afrodescendentes, os povos indígenas, os que estiveram na linha de frente, figurativa e literalmente. Conduru fala sobre a denúncia como "obra aberta", característica do fazer curatorial, que torna públicas "obras, imagens, textos, reflexóes” (CONDURU, 2009, p. 165) que possam ilustrar o discurso do Museu.

Quando Emanoel Araújo, artista afro-brasileiro, transforma a sua seleção de materiais de artistas (afro-brasileiros ou não), poetas, viajantes naturalistas, historiadores, antropólogos, fotógrafos e cientistas sociais em montagens artísticas tâo perceptíveis de sua assinatura porque singulares, não estaria em certa medida tensionando as fronteiras entre arte e curadoria? Sua seleção e releitura destes materiais, compartilhada no formato de exposição, apoiando-se majoritariamente através de imagens não textuais, forma composiçóes singulares que exploram temas sensíveis à memória afro-brasileira. Mesmo quando obras de arte contemporânea figuram em meio a este cenário, é quase impossível dissociá-las do amálgama de objetos que formam a composição.

Tomemos como exemplo a obra O Cortejo, de Nelson Leirner, figura 5. Parte do acervo do Museu, ela reúne imagens de santos do catolicismo popular

\footnotetext{
4 Aqui é importante ressaltar que me refiro à exposição do acervo, tendo em vista que as exposições de curta duração se diferem consideravelmente da de longa duração. É comum que as exposições temporárias reúnam assinaturas de curadores convidados, ou que, ainda que sejam assinadas por Emanoel Araújo, possuam recursos de design e cenografia mais convencionais. Elas também não passam pelo processo de "retroalimentação".
} 
e de entidades de cultos afro-brasileiros em semelhança a uma procissão enfileirada. Exu, Jesus Cristo, Padre Cícero, Nossa Senhora de Fátima e Maria Bonita, entre outros, estão inseridos na mesma plataforma, cercados por pedestais que terminam em bananas dentro de copos de dose. À frente da peça, uma montagem da coleção de ex-votos do Museu, expressóes estéticas do catolicismo popular, que assumem formas diferentes ao redor do mundo, mas no Brasil ganham grande vulto ao redor da figura de Padre Cícero, o "Padin Ciço". Acima da obra de Leirner há um painel com a plotagem de uma montagem digital, que transforma em uma espécie de mandala caleidoscópica, ou talvez, lisérgica, uma imagem não identificada da pintura de um forro de nave central de igreja, provavelmente dos setecentos ou oitocentos. Ao todo temos uma composição, leitura única que fala além dos trabalhos que seleciona, e, através do posicionamento das obras, versa sobre estéticas e metamorfoses do catolicismo no Brasil. Fala sobre o hibridismo das religiosidades e sobre a influência da população afrodescendente na liturgia e imaginário católico. A presença da mão afro-brasileira está ali, não apenas no passado colonizado, mas no presente que se manifesta afrodescendente. Na persistência e reinvenção das religióes de matriz africana no Brasil, e na inserção desta cosmovisão em nosso cotidiano.

Figura 5 - O Cortejo (2009), obra de

Nelson Leirner com composição de Araújo

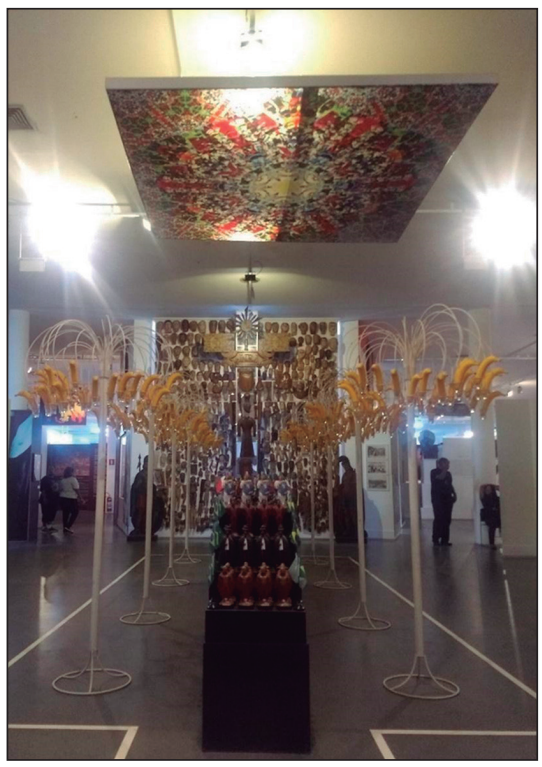

Fonte: Elaboração própria, 2017. 


\section{Considerações finais}

Lançar olhar para uma prática curatorial e expográfica não convencional é ponte para a revisão de nossas categorias e falar sobre fazeres híbridos pode nos ajudar a dimensionar a diversidade das práticas curatoriais e museográficas. Se o discurso institucional é o ponto nevrálgico do Museu, ele se faz percebido em maior ênfase através das exposiçóes; por meio dessas, pode-se fazer com que objetos de natureza distinta conversem entre si, que contem uma história textualmente construída entre eles.

No Afro Brasil, a hierarquia entre textualidade e visualidade da mostra é inexistente. Como propóe Nazareno Almeida (2018), imagens são polissêmicas, e, para além da visualidade, as noçóes de plasticidade e grafia podem ser ressignificadas em razão de sua etimologia. De origem grega, os termos "plástico" e "gráfico", se referiam, respectivamente, a "moldar", e a "marcar", "desenhar", ou "fazer marca" (RIBEIRO, 2018; ALMEIDA, 2018). Portanto, podemos compreender as produçóes imagéticas como uma fusão, que Almeida chama de "plastográfica", da experiência no mundo.

A produção de sentido para as imagens em exposição passa pelo intermédio das práticas discursivas e textuais, no entanto, por vezes, o alfabeto torna-se demasiado diminuto para expressar a infinidade de conexóes possíveis. Por isso o trabalho dos setores educativos, que dialogam com os visitantes e elaboram percursos; do mesmo modo, há os catálogos com a reunião de textos selecionados para mediar as obras escolhidas.

Em campo, percebi que a comunicação não textual como estratégia expográfica pode gerar certo incômodo no público acostumado com a mediação dos textos de parede. Talvez este costume, relacionado à oposição sociocultural entre visualidade e textualidade seja mais facilmente percebido quando aplicado à arte contemporânea, como entrave à fruição deste gênero. Em larga escala, o senso comum dita que é necessário que se tenha um conhecimento pregresso para acessar as informaçóes das propostas artísticas. As imagens criadas por Emanoel Araújo na exposição de longa duração estariam, nesse sentido, próximas a uma obra conceitual, própria à arte contemporânea. Ao fim e ao cabo, estamos diante de um imaginário conceitual que muito nos comunica. $\mathrm{O}$ incômodo ou apatia frente às informaçóes das imagens não podem ser atribuídos aos objetos, mas sim à leitura realizada, à dificuldade de acessar ao que não é usual. Uma visita ao acervo do Museu Afro Brasil pode provocar a reconsideraçáo de conceitos relativos aos museus e suas exposiçóes, algo que só será possível ao pensar - ou repensar - práticas museais. 
Quanto às possibilidades criativas da curadoria, e em que medida se pode em nome deste ofício criar, não há consenso definitivo. Ainda que existam limites e convenções estabelecidas para diferenciar os ofícios de curador e artista, entendo que a "autonomia simbólica" (GONRING, 2015, p. 287), legada ao ofício de curador, é aqui ultrapassada por Emanoel Araújo e sua equipe de curadoria, quando a comunicação que empenham resulta em metalinguagem através das instâncias mencionadas. Concordo com Gabriel Gonring (2015) sobre práticas curatoriais, elas se inscrevem no âmbito da mediação, do desenvolvimento de uma topografia para os objetos expostos. Nesse sentido, o uso da cenografia viria como recurso sensorial, agregado à disposição dos objetos de modo a respeitar os limites do arbiter of taste (MEIJERS, 1996), algo como a autoridade curatorial, o que seria o excesso da autonomia simbólica mencionada por Gonring. No entanto, entendo que nos exemplos elencados acima, bem como em tantos outros que náo caberiam aqui neste texto, Emanuel Araújo excede os limites entre a organização topográfica e os recursos sensoriais da cenografia: não apenas por tensionar o ideal contemporâneo de que o espaço expositivo deveria ser um local com pouca interferência, como ressaltou Rossini (2012), mas, sobretudo pela concomitância dos artifícios do autor. Afinal, por sua experiência como escultor e artista visual, haveria de se presumir que seus feitos enquanto curador extrapolariam a organização espacial dos objetos. Para além disso, ele tece imagens capazes de transmitir a noção de que a presença africana e afrodescendente está muito mais latente em todos os aspectos da nossa sociedade do que admitimos cotidianamente.

\section{REFERÊNCIAS}

ALMEIDA, N. E. de. Mapeando a polissemia da imagem: coisa, forma e evento enquanto modos de significação da plasticidade e da grafia. In: VACCARI, U. R. Arte e Estética. Marília: Oficina Universitária; São Paulo: Cultura Acadêmica, 2018. p. 145-165.

ARAUJO, E. (org.). A mão afro-brasileira: significado da contribuição artística e histórica. 2. ed. rev. e ampl. São Paulo: Imprensa Oficial do Estado de São Paulo/Museu Afro Brasil, 2010.

AUMONT, J. A Imagem. Trad. Estela dos Santos Abreu, Claudio Cesar Santoro. 16. ed. Campinas: Papirus, 2011. 
CONDURU, R. Ogum historiador? Emanoel Araújo e a historiografia da arte afrodescendente no Brasil. In: COLÓQUIO DO COMITÊ BRASILEIRO DE HISTÓRIA DA ARTE, 29.,Vitória, Anais [...], Vitória: Comitê Brasileiro de História da Arte, 2009. Disponível em: http://www.cbha.art.br/pdfs/cbha_2009_conduru_ roberto_art.pdf. Acesso em: 30 jan. 2021.

CUNHA, M. C. da. Negros, estrangeiros: os escravos libertos e sua volta à África. São Paulo: Companhia das Letras, 2012.

FONSECA, S. M. Formação para o trabalho manual no Brasil colônia. 2010. 170 f. Tese (Doutorado em Educação) - Faculdade de Educação, Universidade Estadual de Campinas, Campinas, 2010. Disponível em: http://www.repositorio.unicamp.br/ bitstream/REPOSIP/251204/1/Fonseca_SoniaMaria_D.pdf. Acesso em: 30 jan. 2021.

GONRING, G. M. (O que) pode a curadoria inventar? Galaxia, São Paulo, n. 29, p. 276-288, jun. 2015. Disponível em: http://www.scielo.br/scielo.php?script=sci_arttex t\&pid=S1982-25532015000100276. Acesso em: 30 jan. 2021.

GUARNIERI, W. R. C. A Interdisciplinaridade em Museologia. In: BRUNO, M. C. O. (org.). Waldisa Rússio Camargo Guarnieri: textos e contextos de uma trajetória profissional. São Paulo: Pinacoteca do Estado: Secretaria de Estado da Cultura: Comitê Brasileiro do ICOM, 2010. v.1. Disponível em: https://www.sisemsp.org.br/ download/16440/. Acesso em: 12 fev. 2021.

JESUS, C. C. N. de. Entre escravos e taipas: o modo de fazer africano na arquitetura paulista. História (Sáo Paulo), Assis/Franca, v. 39, p. 1-34, jun. 2020. Disponível em: http://dx.doi.org/10.1590/1980-4369e2020009. Acesso em: 30 jan. 2021.

MEIJERS, D. J. The Museum and the 'Ahistorical' Exhibition. In: FERGUSON, B. W.; GREENBERG, R. Thinking About Exhibitions. London: Routledge, 1996. Chapter 1.

PORTELA, J. C. Metalinguagem Semiótica: empréstimos e redefinições. Cadernos de Semiótica Aplicada, Araraquara, v.10. n.2, p.1-15, dez. 2012. Disponível em: https:// periodicos.fclar.unesp.br/casa/article/view/5598/4402. Acesso em: 30 jan. 2021.

RIBEIRO, C. B. S. Que "Afro” é esse no Afro Brasil?: a concepção curatorial no Museu Afro Brasil - Parque Ibirapuera, São Paulo/SP. 2018.185 f. il. Dissertação (Mestrado em Antropologia Social) - Centro de Filosofia e Ciências Humanas, Universidade Federal de Santa Catarina, Florianópolis, 2018. Disponível em: https:// repositorio.ufsc.br/handle/123456789/189930?show=full. Acesso em: 30 jan. 2021.

ROSSINI, E. Cenografia no teatro e nos espaços expositivos: uma abordagem além da representação. TransInformação, Campinas, v.24, n.3, p.157-164, 2012. Disponível em: http://www.scielo.br/pdf/tinf/v24n3/a01v24n3. Acesso em: 30 jan. 2021. 
SILVA, F. G. da. Pedra e cal: os construtores de vila rica no século XVIII (17301800). 2007. 192 f. Dissertação (Mestrado em História Social) - Faculdade de Filosofia e Ciências Humanas, Universidade Federal de Minas Gerais, Belo Horizonte, 2007. Disponível em: http://hdl.handle.net/1843/VGRO-7BTH7V. Acesso em: 30 jan. 2021.

Recebido em: 10 de setembro de 2020

Aprovado em: 15 de outubro de 2020 